\title{
Differences in Complementary Feeding of 6 to 23 Month Olds in China, US and Mexico
}

\author{
Liya Denney $^{1 *}$, Kathleen C Reidy ${ }^{2}$ and Alison L Eldridge ${ }^{1}$ \\ ${ }^{1}$ Public Health Nutrition, Nestlé Research Centre Lausanne, Switzerland \\ ${ }^{2}$ Nestlé Infant Nutrition, Nestlé Nutrition Global R\&D, Florham Park, NJ, United States
}

Received: November 29, 2016; Accepted: December 15, 2016; Published: December 23, 2016

*Corresponding author: Liya Denney PhD, Public Health Nutrition, Nestlé Research Centre, Vers-chez-les-Blanc, 1000 Lausanne 26, Switzerland. Tel: +41-21-785-8954; Fax: +41-21-785-8561; E-mail: liya.denney@rdls.nestle.com

\begin{abstract}
Background and Aim: Nutritionally adequate complementary food is essential for the optimal growth and development of infants and young children. The aim of the study was to describe and compare the complementary feeding practices in three countries, representing different parts of the world.

Design: Dietary surveys were conducted for infants and young children in China, United States (US) and Mexico. A total of 3103 infants and toddlers aged 6-23 months were included (China $\mathrm{n}=906$, US $n=1430$ and Mexico $n=767$ ). Dietary intake information was collected using 24-hour recalls during face-to-face interviews with the primary caregiver in China and Mexico and via telephone interview in the US. All foods and beverages reported were assigned to food groups adapted from the US Feeding Infants and Toddlers Study. Average amounts of food were calculated and presented for 3 age groups.

Results: Several large differences in complementary food consumption were observed. In China, cow's milk consumption was very low whereas infant formula/growing-up milk was highly consumed (range: $270-317 \mathrm{~g} / \mathrm{d}$ ). Rice was a main grain consumed at all ages. In the US, consumption of vegetable and fruit baby foods resulted in higher vegetable and fruit intakes among infants compared with other countries. $100 \%$ fruit juice was a main beverage and highly consumed at all ages. In Mexico, infant cereal consumption was low, while a substantial amount of cow's milk was consumed before 12 months of age. Sugar sweetened beverage and sweets were highly consumed at all ages (range: $64-219 \mathrm{~g} / \mathrm{d}$ ).
\end{abstract}

Conclusions: Complementary food consumption varied considerably across the 3 countries. Early feeding of relatively high amounts of empty calorie foods, such as sugar sweetened beverages and sweets and high consumption of low-nutrient dense food such as rice was observed. These findings provide culture-specific and foodbased information for healthcare professionals in these countries to offer more targeted guidance on improving complementary feeding practices.

Keywords: Complementary Feeding; Infants; Toddlers; China; US; Mexico

\section{Introduction}

The introduction of suitable complementary foods at the appropriate time is essential for the optimal growth and development of infants and young children. Complementary foods should be added to the diet when breast milk is no longer sufficient to meet the nutritional needs of the infant [1]. The transition from exclusive breastfeeding to family foods, referred to as complementary feeding, typically covers the period from 6 to 18-24 months of age [1]. Since children under two years of age have high nutrient needs to support their rapid growth and development but consume relatively small amounts of food at a time, complementary foods need to be far more nutrient-dense than foods consumed by adults [2].

The introduction of complementary food is influenced by cultural and traditional beliefs [3-5]. Food culture and habits in a country influence the ability to meet nutritional needs of infants and young children during the feeding transition. We have previously reported risk of inadequate intakes of fat, vitamin B6 and folate and high sodium intake in China [6] and low fiber and high saturated fat intakes that exceeded recommendations in the US [7]. In addition, we have reported high proportions of infants and young children consume sugar sweetened beverages and sweets in the US and Mexico [8, 9] and high proportions of infants and young children in China consume refined rice while low proportions consume vegetables [10].

Up to now, quantities of complementary foods have not been reported and few studies have compared differences in complementary foods consumed and how consumption of major food groups shifts with age across different parts of the world. This type of information can be useful for health professionals as it provides context to understand culture-specific complementary feeding practices. Hence, the aim of this study is to describe and compare complementary foods consumed in China, US and Mexico using data from the dietary surveys conducted in the three countries.

\section{Materials and methods}

\section{Subjects}

Food intake data were obtained from three sources: the Maternal Infant Nutrition Growth (MING) study in China [6], the Feeding Infants and Toddlers Study 2008 (FITS) in the US [11], and the Mexico National Health and Nutrition Survey 2012 
(NHNS), also known as Encuesta Nacional de Salud y Nutrición in Mexico [12].

The MING study was a cross-sectional study to investigate the dietary and nutritional status of pregnant women, lactating mothers, and infants and young children conducted in 2011 and $2012[6,13]$. Infants and young children aged from birth to 35 months were recruited from maternal and child care centers (MCCC) in eight cities in China. In each city, two MCCC were selected and subjects were recruited randomly based on the child registration list in each of the MCCC until the target number was reached. The study was conducted according to the guidelines in the Declaration of Helsinki. All of the procedures involving human subjects were approved by the Medical Ethics Research Board of Peking University. Written informed consent was obtained from the primary caregiver of each child participating in the study. A total of 906 of infants and toddlers aged 6-23 months were included in the current analysis.

The FITS 2008 was a national sample of US children aged from birth through age 47 months [11]. Subjects were recruited and interviews were conducted by telephone. All instruments and procedures were reviewed and approved by Mathematica Policy Research's independent institutional review board (Public/ Private Ventures, Philadelphia, PA). A total of 1430 of infants and toddlers aged 6-23 months were included in the current analysis.

The Mexican NHNS 2012 was a cross-sectional population based survey to characterize the health and nutritional status of the Mexican population. The survey used a multi-stage, stratified and clustered sampling system drawn to be representative of all states and four geographic regions in Mexico [12]. The survey protocol and data collection instruments were approved by the Ethics Committee of the Mexican National Institute of Public Health. A total of 767 of infants and toddlers aged 6-23 months from the NHNS were included in the current analysis.

\section{Dietary data collection}

In the MING study in China and NHNS in Mexico, one 24-hour dietary recall was collected for each child through a face-to-face interview by trained interviewers with the parent or caregiver. The interviewers asked about all foods and beverages and the amount consumed of each food item for the previous 24-hour period. Portions were estimated using common household measurement aids (including spoons, cups and bowls) and the information was then converted to grams. A picture booklet of common foods consumed was also used to estimate the amount of foods and beverages in the MING study.

In FITS, two 24-hour dietary recalls were collected via telephone interview conducted by certified dietary interviewers at the University of Minnesota's Nutrition Coordinating Center using the Nutrition Data System for Research (version 2008, University of Minnesota Nutrition Data System for Research, Minneapolis). Before the dietary interview, the main caregiver of the selected child was mailed a packet of materials, including food model booklet, ruler, and liquid measuring cup with instructions for estimating amounts of foods and beverages consumed. Food intake data collected on first day of the two 24 hour recalls was used in the present analysis.

All foods and beverages reported were assigned to food groups adapted from FITS [14]. Food groups were adjusted for China and Mexico to incorporate local foods and reflect the relative role of specific types of foods in the diets of infants and toddlers living in those countries. In China, fortified milk power produced specifically for young children aged 1-3 years, called growing-up milk, is commonly consumed by young children from 12 months onwards. In this study, infant formula and growingup milk were grouped into one category called infant formula/ growing-up milk.

Breast milk consumption was estimated based on the child's age in months and the total amount of other milks (infant formula and cow's milk) reported over the course of the recall day $[7,15]$. The same estimates were used for children in all three countries. For infants aged 6 to 11 months fed human milk as the sole milk source, the amount of human milk was assumed to be $600 \mathrm{~mL} /$ day. For partially breastfed infants, the amount of human milk was computed as $600 \mathrm{~mL} /$ day minus the amount of formula/ other milks consumed. For breastfed young children aged 12 to 17 months, the amount of human milk was computed as $89 \mathrm{~mL}$ per feeding occasion. For breastfed young children aged 18 to 23 months, the amount of human milk was computed as $59 \mathrm{~mL}$ per feeding occasion $[7,15]$.

\section{Analytic methods}

Average amount of foods and beverages consumed in grams per capita and Standard Errors (SE) were calculated using the Statistical Analysis System (version 9.1.3, 2004, SAS Institutes, Cary, NC). In FITS and NHNS, all estimates incorporated appropriate sample weights to reflect nationally representative results and to account for survey design. In the MING study, sample weighting was not carried out as the study was not designed to collect a nationally representative sample [6]. To understand complementary food consumption in detail and changes with age, average amounts of complementary foods consumed were presented for three age groups: 6-8 months, 9-11 months and 12-23 months for each country. Differences in mean intake between age groups in each country and differences in mean intake between countries for the same age group were tested by using Student's $t$ tests. A null hypothesis was rejected at an $\alpha$ level that controls the overall type I error rate at $5 \%$ by using Bonferroni correction for multiple comparisons [16].

\section{Results}

\section{Milk}

Breast milk constituted about half of the milk intake and formula the other half among 6-8 month olds in both China and Mexico (Table 1). In the US, breast milk was consumed at a lower level and the level remained unchanged among 9-11 month olds. In China, breast milk consumption decreased significantly by 9-11 month ( $\mathrm{p}<0.01)$. By 12-23 months, breast milk consumption decreased sharply in all counties $(\mathrm{p}<0.01)$ (Table 1$)$. 
Large differences were seen in formula/growing-up milk and cow's milk consumption across countries. In China, infant formula/growing-up milk was the major source of milk consumed across all age groups and its consumption was still high at 12-23 months, with an average amount of $317 \mathrm{~g} / \mathrm{d}$ (equal to approximately 1.25 cups per day) (Table 1 ). On the other hand, cow's milk consumption was very low across all age groups. In the US, at 6-8 months and 9-11 months, infant formula was consumed at a higher amount (526 g/d and $484 \mathrm{~g} / \mathrm{d}$, respectively), nearly twice as much as what was consumed among Chinese infants ( $p<0.01$ ). By 12-23 months, cow's milk became the major source of milk with children consuming on average $408 \mathrm{~g} / \mathrm{d}$ (equivalent to 1.7 cups per day). In Mexico, infant formula was consumed both before and after 12 months but the amount was lower after 12 months $(\mathrm{p}<0.05)$. It was also observed that in the Mexican population cow's milk was already consumed at a significant amount $(210 \mathrm{~g} / \mathrm{d})$ by $9-11$ months compared with other two countries $(p<0.01)$ and it remained to be the main source of milk at 12-23 months (Table 1 ).

\section{Grains}

In China, infant cereal was one of the main grain sources at both 6-8 months and 9-11 months (Table 1). Rice was another main grain source at 6-8 months and its consumption increased steadily and sharply with age $(\mathrm{p}<0.01)$. By $12-23$ months the average amount of rice consumed was $96 \mathrm{~g} / \mathrm{d}$. In the US, infant cereal was the major grain source at 6-8 months and family cereals became another major grain source from 9-11 months onwards. Rice and pancakes/tortilla were consumed at a lower amount (Table 1). Among Mexico children, pancakes/tortilla was the major grain source by $12-23$ months $(29 \mathrm{~g} / \mathrm{d})$. Other grains including infant cereal, family cereals and rice were also consumed (Table 1).

\section{Desserts/sweets/sugar-sweetened beverages and fruit juice}

For desserts/sweets/sugar-sweetened beverages (SSB) and fruit juice, distinct consumption patterns were observed. In China, desserts/sweets/SSB or fruit juice were rarely consumed (Table 2 and Fig. 1), whereas in the US, sweet food and beverage consumption increased steadily with age $(\mathrm{p}<0.05)$, with SSB the largest contributor at 12-23 months. In Mexico, similar patterns to the US, but on a very different scale, were observed. SSB consumption was 2 fold higher at 9-11 months and more than 3 fold higher at 12-23 months than in the US. The average amount of SSB was $219 \mathrm{~g} / \mathrm{d}$ at 12-23 months (Table 2 and Fig 1). Although the consumption of SSB in the US was not as high as that in Mexico, $100 \%$ fruit juice however was highly consumed $(\mathrm{p}<0.01)$. The average amount was $139 \mathrm{~g} / \mathrm{d}$ at 12 to 23 months (approximately $1 / 2$ cup).

\section{Fruit and Vegetables}

Generally, before 12 months of age consumption of vegetables, especially different types of colored vegetables, was low in Mexico and China, compared to the US ( $\mathrm{p}<0.05$ ) (Table 3). In China, any vegetable consumption increased at 12-23 months $(\mathrm{p}<0.05)$, whereas in the US any vegetable consumption peaked between 9-11 months, then decreased at 12-23 months ( $\mathrm{p}<0.05)$ (Table 3). The higher vegetable consumption in the US can be attributed to the consumption of vegetable baby food $(61 \mathrm{~g} / \mathrm{d}$ at 6-8 months and $42 \mathrm{~g} / \mathrm{d}$ at 9-11 months) (Table 3). In Mexico, any vegetable consumption fluctuated at a lower level compared with other two populations and no age related change was observed. However, the amount of vegetables consumed was likely underestimated as it was not possible to disaggregate vegetables from mixed dishes in the Mexico survey.

Any fruit consumption was higher in the US than in China at 6-8 months and at 9-11 months $(\mathrm{p}<0.05)$ (Table 2). Again, fruit baby foods were a major contributor to overall fruit consumption in the US, but rarely or little consumed in China and Mexico $(p<0.01)$. Any fruit consumption at $9-11$ months increased significantly from 6-8 months in the US $(\mathrm{p}<0.01)$ but this was not observed in China and Mexico.

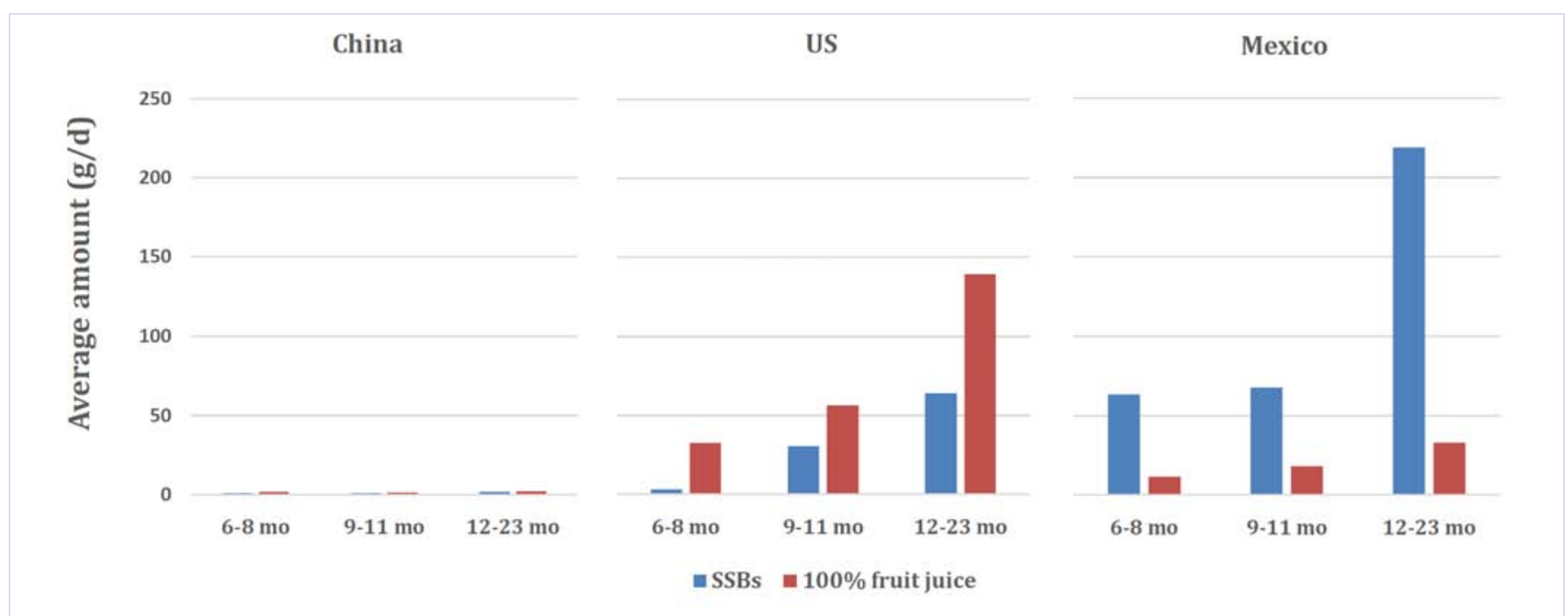

Figure 1: Sugar sweetened beverage (SSB) and 100\% fruit juice consumption of infants and toddlers from China, US and Mexico. 
Table 2: Daily consumption per capita of fruits and desserts, sweets and sugar-sweetened beverages of infants and young children from China, the US and Mexico

\begin{tabular}{|c|c|c|c|c|c|c|c|c|c|}
\hline \multirow[b]{3}{*}{ Food group/food } & \multicolumn{9}{|c|}{ Age group (months) } \\
\hline & \multicolumn{3}{|c|}{ China } & \multicolumn{3}{|c|}{ US } & \multicolumn{3}{|c|}{ Mexico } \\
\hline & $\begin{array}{c}6-8 \\
(n=201)\end{array}$ & $\begin{array}{c}9-11 \\
(n=235)\end{array}$ & $\begin{array}{c}12-23 \\
(n=476)\end{array}$ & $\begin{array}{c}6-8 \\
(n=249)\end{array}$ & $\begin{array}{c}9-11 \\
(n=256)\end{array}$ & $\begin{array}{c}12-23 \\
(n=925)\end{array}$ & $\begin{array}{c}6-8 \\
(n=107)\end{array}$ & $\begin{array}{c}9-11 \\
(n=122)\end{array}$ & $\begin{array}{c}12-23 \\
(n=538)\end{array}$ \\
\hline & \multicolumn{9}{|c|}{ Mean (standard error) g/d } \\
\hline \multicolumn{10}{|l|}{ Fruits } \\
\hline Any Fruit $(g / d)^{1,2}$ & $37(8)^{\mathrm{u}^{*}}$ & $57(14)^{u^{*}}$ & $86(14)$ & $68(7)$ & $109(12)^{\ddagger \neq, m^{*}}$ & $114(6)$ & $48(9)$ & $60(16)$ & $91(9)$ \\
\hline \multicolumn{10}{|l|}{ Types of fruits } \\
\hline Fruit baby food (g/d) & $0^{\mathrm{u}^{* *}}$ & $1(0)^{\mathrm{u}^{* *}}$ & $0^{\mathrm{u}^{* *}}$ & $55(7)^{\mathrm{m}^{* *}}$ & $54(9)^{\mathrm{m}^{* *}}$ & $10(2)^{\ddagger \neq, m^{* *}}$ & $13(5)^{\mathrm{c}^{* *}}$ & $7(3)^{\mathrm{c}^{*}}$ & $2(1)^{\ddagger}$ \\
\hline Apples (g/d) & $19(3)$ & $30(4)^{\ddagger}$ & $30(5)$ & $28(5)^{\mathrm{m}^{* *}}$ & $33(7)^{\mathrm{m}^{* *}}$ & $27(3)^{\mathrm{m}^{* *}}$ & $0^{\mathrm{c}^{* *}}$ & $0^{\mathrm{c}^{* *}}$ & $0^{c^{* *}}$ \\
\hline Bananas (g/d) & $5(1)^{u^{* *}}$ & $8(2)^{\mathrm{u}^{* *}}$ & $12(3)^{u^{* *}}$ & $24(4)$ & $31(7)$ & $24(2)^{\mathrm{m}^{*}}$ & $20(6)^{c^{* *}}$ & $20(5)^{c^{*}}$ & $34(4)^{\mathrm{c}^{* *}}$ \\
\hline Citrus fruits (g/d) & $2(1)$ & $8(2)^{\ddagger}$ & $19(4)^{u^{* *}}$ & 0 & $5(3)$ & $6(1)^{\mathrm{m}^{*}}$ & 0 & $0^{c^{*}}$ & $0^{c^{* *}}$ \\
\hline $100 \%$ fruit juice $(\mathrm{g} / \mathrm{d})$ & $1(1)^{\mathrm{u}^{* *}}$ & $1(1)^{u^{* *}}$ & $2(1)^{u^{* *}}$ & $32(6)$ & $56(9)^{\ddagger} m^{*}$ & $139(10)^{\ddagger \neq, \mathrm{m}^{* *}}$ & $12(5)^{\mathrm{c}^{*}}$ & $18(6)^{\mathrm{c}^{* *}}$ & $33(6)^{\mathrm{c}^{* *}}$ \\
\hline \multicolumn{10}{|l|}{$\begin{array}{c}\text { Desserts/sweets and } \\
\text { beverages }\end{array}$} \\
\hline $\begin{array}{l}\text { All Desserts/Sweets/SSB } \\
\qquad(\mathrm{g} / \mathrm{d})\end{array}$ & $1(1)$ & $1(1)^{\mathrm{u}^{* *}}$ & $5(3)^{\mathrm{u}^{* *}}$ & $8(3)^{\mathrm{m}^{* *}}$ & $49(18)^{\ddagger}$ & $98(7)^{\ddagger \neq, m^{* *}}$ & $70(22)^{\mathrm{c}^{* *}}$ & $91(15)^{c^{*}}$ & $256(26)^{\ddagger \neq, c^{* *}}$ \\
\hline Cakes/pies/cookies (g/d) & $1(0)$ & $1(0)^{u^{*}}$ & $3(2)^{\mathrm{u}^{* *}}$ & $1(0)^{m^{*}}$ & $4(1)^{\ddagger \ddagger, m^{*}}$ & $14(2)^{\text {㧊 }}$ & $4(1)^{c^{* *}}$ & $14(5)^{c^{* *}}$ & $13(2)^{\mathrm{c}^{* *}}$ \\
\hline $\begin{array}{l}\text { Ice cream/frozen yogurt } \\
\text { (g/d) }\end{array}$ & 0 & 0 & $0^{\mathrm{u}^{* *}}$ & 0 & $1(1)$ & $10(2)^{\ddagger}$ & $1(1)$ & $2(1)^{\mathrm{c}^{*}}$ & $4(1)^{\mathrm{c}^{* *}}$ \\
\hline $\mathrm{SSB}(\mathrm{g} / \mathrm{d})^{3}$ & 0 & 0 & $1(1)^{u^{* *}}$ & $3(3)^{\mathrm{m}^{* *}}$ & $30(18)$ & $64(7)^{\ddagger, m^{* *}}$ & $64(22)^{\mathrm{c}^{* *}}$ & $68(15)^{\mathrm{c}^{* *}}$ & $219(26)^{f \neq, c^{* *}}$ \\
\hline Sweet bread (g/d) & 0 & 0 & $0^{u^{*}}$ & 0 & $1(0)$ & $4(1)^{\mathrm{m}^{*}}$ & $1(0)^{\mathrm{c}^{* *}}$ & $2(1)^{c^{*}}$ & $12(2)^{\ddagger, c^{* *}}$ \\
\hline \multicolumn{10}{|c|}{$\begin{array}{l}{ }^{1} \text { All fruit are included in the total but not all the individual items are list here. } \\
{ }^{2} \text { Does not include } 100 \% \text { juice } \\
\text { 3 Includes fruit flavored drinks, carbonated sodas and sweetened tea/coffee. } \\
{ }^{\ddagger} \mathrm{p}<0.05 \text {; }{ }^{*} \mathrm{P}<0.019-11 \text { for group months vs group } 6-8 \text { months and group } 12-23 \text { months vs group } 9-11 \text { months within country. } \\
\text { uChina vs. US, }{ }^{\mathrm{m}} \text { US vs. Mexico, }{ }^{c} \text { Mexico vs. China for the same age group; }{ }^{*} \mathrm{P}<0.05,{ }^{* *} \mathrm{P}<0.01 \text {. }\end{array}$} \\
\hline
\end{tabular}

believed to help with digestion. However, refined rice or rice products are of low energy and micronutrient density. Without fortification refined rice products provide insufficient quantities of iron, zinc and calcium. When such foods that are poor sources of nutrients become major sources in the diet, the risk of nutrient shortfall could exist [6].

In the US, family cereals were a major grain source from the age of 9-11 months while infant cereal consumption was diminishing. Ready-to-eat cereals are often fortified with micronutrients, though generally at a lower level than fortified infant cereal. Indeed, family cereals were reported to be top sources of iron and zinc among infants and young children from FITS previously [14]. To a lesser extent, family cereals were also consumed among the Mexican children and a variety of other grains were consumed by Mexican children including pancakes/ tortilla, pasta, noodles and rice.

Large differences were found in SSB and fruit juice consumption. SSBs were rarely consumed among the Chinese children but were heavily consumed among the Mexican children with the average amount alarmingly high. The high amount of SSB consumption adds further insight to our previous report that 63-
$78 \%$ of the Mexican children consumed SSB on the day of dietary recall [8]. SSBs such as water- and milk-based atoles, Aguas Frescas, fruit flavored drinks, sweetened tea and carbonated soft-drinks were the primary sources of added sugar in the diet of children. Consumption of SSBs has been positively associated with overweight and obesity in infants and children in Mexico, US and UK $[26,27]$. Obesity during childhood and adolescence is of major concern given that obese children and adolescents are at higher risk of being obese adults and developing comorbidities, such as diabetes and cardiovascular diseases [28-30].

Although fruit juice is a major source of vitamin $\mathrm{C}$ and potassium, 100\% fruit juice consumption has been questioned as another high-calorie, high sugar food increasing likelihood of obesity in preschoolers [31-33]. The American Academy of Pediatrics recommends limiting juice to 4-6 ounces per day for children ages 1-6 years [34]. The average amount of fruit juice consumed by toddlers 12-23 months in FITS was about 5 ounces per day. Considering these children's young age, the consumption of fruit juice should be closely monitored and perhaps reduced among high consumers.

We acknowledge that our study has limitations. First, all 
Table 3: Daily consumption per capita of vegetables, meat or protein food of infants and young children from China, the US and Mexico

\begin{tabular}{|c|c|c|c|c|c|c|c|c|c|}
\hline \multirow[b]{3}{*}{ Food group/food } & \multicolumn{9}{|c|}{ Age group (months) } \\
\hline & \multicolumn{3}{|c|}{ China } & \multicolumn{3}{|c|}{ US } & \multicolumn{3}{|c|}{ Mexico } \\
\hline & $\begin{array}{c}6-8 \\
(n=201)\end{array}$ & $\begin{array}{c}9-11 \\
(n=235)\end{array}$ & $\begin{array}{c}12-23 \\
(n=476)\end{array}$ & $\begin{array}{c}6-8 \\
(n=249)\end{array}$ & $\begin{array}{c}9-11 \\
(n=256)\end{array}$ & $\begin{array}{c}12-23 \\
(n=925)\end{array}$ & $\begin{array}{c}6-8 \\
(n=107)\end{array}$ & $\begin{array}{c}9-11 \\
(n=122)\end{array}$ & $\begin{array}{c}12-23 \\
(n=538)\end{array}$ \\
\hline Vegetables & \multicolumn{9}{|c|}{ Mean (standard error) g/d } \\
\hline Any vegetables ${ }^{1,2}$ & $17(10)^{\mathrm{u}^{* *}}$ & $30(12)^{\mathrm{u}^{* *}}$ & $59(8)^{\ddagger}$ & $76(9)^{\mathrm{m}^{* *}}$ & $92(12)^{\mathrm{m}^{*}}$ & $64(4)^{\ddagger, m^{* *}}$ & $19(10)$ & $38(12)$ & $24(5)^{\mathrm{c} * *}$ \\
\hline \multicolumn{10}{|l|}{ Types of vegetables } \\
\hline Vegetable baby food & $0^{u^{* *}}$ & $0^{u^{* *}}$ & $0^{\mathrm{u}^{* *}}$ & $61(7)^{\mathrm{m}^{* *}}$ & $42(6)^{\ddagger, m^{* *}}$ & $9(2)^{\ddagger \neq, m^{*}}$ & $3(2)$ & $3(2)$ & $1(1)$ \\
\hline Dark green vegetables ${ }^{3}$ & $4(2)$ & $6(3)$ & $11(5)$ & $1(1)$ & $18(12)^{\mathrm{m}^{*}}$ & $6(2)$ & 0 & $0^{\mathrm{c}^{* *}}$ & 0 \\
\hline Deep yellow vegetables ${ }^{4}$ & $4(4)^{u^{* *}}$ & $5(3)^{u^{* *}}$ & $9(4)$ & $36(6)^{\mathrm{m}^{* *}}$ & $30(5)^{\mathrm{m}^{* *}}$ & $12(2)^{\ddagger \neq, m^{* *}}$ & $4(4)$ & $5(3)$ & $1(1)$ \\
\hline White potatoes & $1(1)$ & $1(0)^{\mathrm{u}^{* *}}$ & $3(1)^{u^{* *}}$ & $9(7)$ & $11(3)$ & $19(2)^{\mathrm{m}^{* *}}$ & $5(5)$ & $3(2)$ & $7(3)$ \\
\hline Other vegetables ${ }^{5}$ & $9(6)$ & $18(3)$ & $39(6)^{ \pm, u^{* *}}$ & $21(5)^{\mathrm{m}^{*}}$ & $24(5)^{\mathrm{m}^{* *}}$ & $19(2)$ & $1(1)$ & $2(2)^{c^{* *}}$ & $13(3)^{\mathrm{c} * *}$ \\
\hline \multicolumn{10}{|l|}{ Meat/protein sources } \\
\hline Cheese & 0 & $0^{u^{*}}$ & $0^{\mathrm{u}^{* *}}$ & $1(1)$ & $3(1)$ & $8(1)^{\ddagger}$ & $1(1)$ & $5(3)$ & $10(5)$ \\
\hline Yogurt & 0 & $1(1)^{u^{* *}}$ & $10(4)^{u^{* *}}$ & $6(3)^{m^{*}}$ & $12(2)$ & $26(3)^{\ddagger}$ & $24(9)^{c^{* *}}$ & $22(5)^{c^{* *}}$ & $25(3)^{\mathrm{c} * *}$ \\
\hline Beef & 0 & 0 & $1(1)$ & 0 & $1(0)$ & $7(2)$ & $4(5)$ & $8(5)$ & $2(1)$ \\
\hline Chicken or turkey & 0 & $1(1)^{u^{*}}$ & $4(2)^{\mathrm{u}^{* *}}$ & $2(1)$ & $9(3)^{\ddagger}$ & $17(1)^{\ddagger \neq}$ & $1(1)$ & $3(2)$ & $23(8)$ \\
\hline Fish or shellfish & $2(2)$ & $5(1)^{u^{* *}}$ & $10(3)^{\mathrm{u}^{* *}}$ & 0 & 0 & $2(1)$ & 0 & $0^{c^{* *}}$ & $2(2)$ \\
\hline Pork/ham & $5(1)^{u^{*}}$ & $8(1)^{\ddagger, u^{* *}}$ & $20(3)^{\ddagger \neq, u^{* *}}$ & $1(1)$ & $1(1)$ & $4(1)$ & $0^{\mathrm{c}^{* *}}$ & $0^{\mathrm{c}^{* *}}$ & $1(1)^{\mathrm{c} *^{* *}}$ \\
\hline Eggs & $24(4)^{\mathrm{u}^{* *}}$ & $33(3)^{u^{* *}}$ & $39(4)^{\mathrm{u}^{* *}}$ & $0^{\mathrm{m}^{* *}}$ & $4(1)^{\ddagger \neq, m^{*}}$ & $13(2)^{\ddagger, m^{* *}}$ & $13(8)$ & $23(11)$ & $32(4)$ \\
\hline Meat baby food & $0^{u^{*}}$ & 0 & 0 & $3(1)$ & $1(0)^{\ddagger}$ & $1(0)$ & $2(2)$ & $1(1)$ & $1(1)$ \\
\hline $\begin{array}{c}\text { Dried beans, peas, meat } \\
\text { substitutes }\end{array}$ & $3(1)$ & $3(1)$ & $10(3)$ & $1(0)^{\mathrm{m}^{* *}}$ & $1(0)^{\mathrm{m}^{* *}}$ & $8(2)^{\mathrm{m}^{* *}}$ & $10(4)$ & $10(3)^{c^{*}}$ & $28(4)^{\ddagger, c^{* *}}$ \\
\hline
\end{tabular}

${ }^{1}$ Any vegetables from mixed dishes in Mexico are not included because they cannot be disaggregated.

${ }^{2}$ Different grouping in US. Cooked vegetables and $100 \%$ vegetable juice were included in each types of vegetables

${ }^{3}$ Reported dark-green vegetables include broccoli, spinach and other greens, and romaine lettuce.

${ }^{4}$ Reported deep-yellow vegetables include carrots, pumpkin, sweet potatoes and winter squash.

${ }^{5}$ Other reported vegetables include artichoke, asparagus, beets, Brussels sprouts, cabbage, cauliflower, celery, cucumber, eggplant, green beans, lettuce, mushrooms, onions, peapods, peppers, tomatoes/tomato sauce and summer squash.

${ }^{\ddagger} \mathbf{p}<0.05 ;{ }^{\ddagger} \mathrm{P}<0.01$ 9-11 for group months vs group 6-8 months and group 12-23 months vs group 9-11 months within country.

${ }^{\mathrm{u}}$ China vs. US, ${ }^{\mathrm{m}}$ US vs. Mexico, ${ }^{\mathrm{c}}$ Mexico vs. China for the same age group; ${ }^{*} \mathrm{P}<0.05,{ }^{* *} \mathrm{P}<0.01$.

children in the MING study were recruited from the MCCC in selected cities in China, Therefore, it was an urban rather than a nationally representative sample. Indeed, it has been reported that the proportion of young children consuming meat or milk is higher in urban than in rural areas in China [35]. Therefore, the MING data reported in this study reflects mainly complementary feeding practices in urban areas of China. Second, the information on food consumption in China and Mexico was based on one 24-h dietary recall. It is possible that for some children the recall day was not typical of their usual dietary pattern. However, validated methods for collection by trained interviewers and the large sample sizes may help to minimize these issues [36]. Nevertheless, a major strength of our study is the use of same age categories and food groups to describe the complementary food intake and transitions across the ages of 6 to 23 months in three countries representing different parts of the world.

\section{Conclusions}

This study described the infant feeding transitions across the ages of 6 to 23 months in three culturally diverse populations. Complementary food consumption varied considerably across the three countries. This study confirmed and provided additional detail about some problematic feeding patterns identified earlier across the three countries, including early introduction of relatively high amounts of empty calorie foods, such as SSB and sweets in Mexico and US, and high consumption of low-nutrient dense foods such as refined rice in China. We also observed an early introduction of cow's milk in Mexico along with low intake of iron-rich foods like iron-fortified infant cereal. Infant feeding guidelines should be culture-specific and food-based. The findings from the study will help healthcare professionals to target advice to parents on improving complementary feeding practices in these countries.

\section{Acknowledgements}

The authors thank the families who volunteered for this study, Laurence Li for project support and guidance, Celia Ning and Gerard Vinyes-Parés for project management, Yumei Zhang and her colleagues for study execution and data collection and local project staff for recruitment.

\section{Declarations}

Conflicts of Interest: There is no conflict of interest to disclose. Liya Denney, Alison L. Eldridge and Kathleen C. Reidy are employees of Nestec, SA (Nestle Research Center), Lausanne, Switzerland. The opinions expressed in the article are those of the authors alone and do not necessary reflect the views of recommendations of their affiliations. 
Ethical Approval: The MING study in China was by the Medical Ethics Research Board of Peking University. The NHNS survey protocol and data collection instruments were approved by the Ethics Committee of the Mexican National Institute of Public Health. The FITS survey procedures and instruments were approved by Mathematician Policy Research's independent institutional review board (Public/Private Ventures, Philadelphia, PA). Written informed consent was obtained from the primary caregiver of each child participating in all the above surveys.

\section{References}

1. PAHO/WHO. Guiding principles for complementary feeding of the breastfed child. Washington DC: Pan American Health Organization/ World Health Organization; 2002.

2. Dewey KG. The challenge of meeting nutrient needs of infants and young children during the period of complementary feeding: an evolutionary perspective. J Nutr. 2013;143(12):2050-2054. doi: 10.3945/jn.113.182527.

3. Inoue $\mathrm{M}$, Binns $\mathrm{CW}$. Introducing solid foods to infants in the Asia Pacific region. Nutrients. 2014;6(1):276-288. doi: 10.3390/nu6010276.

4. Pelto GH, Armar-Klemesu M, Siekmann J, Schofield D. The focused ethnographic study 'assessing the behavioral and local market environment for improving the diets of infants and young children 6 to 23 months old' and its use in three countries. Matern Child Nutr. 2013;9 Suppl 1:35-46. doi: 10.1111/j.1740-8709.2012.00451.x.

5. Galvin S, Grossman X, Feldman-Winter L, Chaudhuri J, Merewood A. A practical intervention to increase breastfeeding initiation among Cambodian women in the US. Matern Child Health J. 2008;12(4):545547. doi: 10.1007/s10995-007-0263-7.

6. Chen C, Denney L, Zheng Y, Gerard Vinyes-Pares,Kathleen Reidy, Huan Wang, et al. Nutrient intakes of infants and toddlers from maternal and child care centres in urban areas of China, based on one 24-hour dietary recall. BMC Nutrition. 2015;1:23. doi: 10.1186/ s40795-015-0019-5.

7. Butte NF, Fox MK, Briefel RR, Siega-Riz AM, Dwyer JT, Deming DM, et al. Nutrient intakes of US infants, toddlers, and preschoolers meet or exceed dietary reference intakes. J Am Diet Assoc. 2010;110(12 Suppl): S27-37. doi: 10.1016/j.jada.2010.09.004.

8. Deming DM, Afeiche MC, Reidy KC, Eldridge AL, Villalpando-Carrión S Early feeding patterns among Mexican babies: findings from the 2012 National Health and Nutrition Survey and implications for health and obesity prevention. BMC Nutrition. 2015;1:40. doi: 10.1186/s40795015-0035-5.

9. Siega-Riz AM, Deming DM, Reidy KC, Fox MK, Condon E, Briefel RR, et al. Food consumption patterns of infants and toddlers: where are we now? J Am Diet Assoc. 2010;110(12 Suppl):S38-51. doi: 10.1016/j. jada.2010.09.001.

10. Yu P, Denney L, Zheng Y, Vinyes-Parés G, Reidy KC, Eldridge AL, et al. Food groups consumed by infants and toddlers in urban areas of China. Food Nutr Res. 2016;60:30289. doi: 10.3402/fnr.v60.30289.

11. Briefel RR, Kalb LM, Condon E, Deming DM, Clusen NA, Fox MK, et al. The Feeding Infants and Toddlers Study 2008: study design and methods. J Am Diet Assoc. 2010;110(12 Suppl):S16-26. doi: 10.1016/j. jada.2010.09.005.

12. Piernas C, Miles DR, Deming DM, Reidy KC, Popkin BM. Estimating usual intakes mainly affects the micronutrient distribution among infants, toddlers and pre-schoolers from the 2012 Mexican National Health and Nutrition Survey. Public Health Nutr. 2016;19(6):10171026. doi: $10.1017 /$ S1368980015002311.
13.Wang H, Denney L, Zheng Y, Gerard Vinyes-Pares,Kathleen Reidy, Peiyu Wang et al. Food sources of energy and nutrients in the diets of infants and toddlers in urban areas of China, based on one 24-hour dietary recall. BMC Nutrition. 2015;1:19. doi: 10.1186/s40795-0150014-X.

14. Fox MK, Reidy K, Novak T, Ziegler P. Sources of energy and nutrients in the diets of infants and toddlers. J Am Diet Assoc. 2006;106(1 Supp 1):S28-42. doi: 10.1016/j.jada.2005.09.034.

15. Devaney B, Ziegler P, Pac S, Karwe V, Barr SI. Nutrient intakes of infants and toddlers. J Am Diet Assoc. 2004;104: s14-21. doi: 10.1016/j. jada.2003.10.022.

16. Armstrong RA. When to use the Bonferroni correction. Ophthalmic Physiol Opt. 2014;34(5):502-508. doi: 10.1111/opo.12131.

17.Ge K. The transition of Chinese dietary guidelines and food guide pagoda. Asia Pac J Clin Nutr. 2011;20(3): 439-446.

18. Tang L, Lee AH, Binns CW, Yang Y, Wu Y, Li Y, et al. Widespread usage of infant formula in China: a major public health problem. Birth. 2014;41(4):339-343. doi: 10.1111/birt.12132.

19.Zhang K, Tang L, Wang H, Li-Qian Qiu, Colin W Binns, Andy H Lee. Why do mothers of young infants choose to formula feed in China? Perceptions of mothers and hospital staff. Int J Environ Res Public Health. 2015;12(5):4520-4532. doi: 10.3390/ijerph120504520.

20. WHO. Guideline: Sugars intake for adults and children. Geneva: World Health Organization; 2015.

21. Griebler U, Bruckmuller MU, Kien C, Dieminger B, Meidlinger B, Seper $\mathrm{K}$, et al. Health effects of cow's milk consumption in infants up to 3 years of age: a systematic review and meta-analysis. Public Health Nutr. 2016;19(2):293-307. doi: 10.1017/S1368980015001354.

22. de la Cruz-Gongora V, Villalpando S, Mundo-Rosas V, Shamah-Levy T. [Prevalence of anemia in Mexican children and adolescents: Results from three national surveys]. Salud Pública de México. 2013;55 Suppl 2:S180-189.

23. Chinese Nutrition Society. Chinese Dietary Guidelines. Acta Nutrimenta Sinica. 2008;30:2-18.

24. Butte N, Cobb K, Dwyer J, Graney L, Heird W, Rickard K, et al. The Start Healthy Feeding Guidelines for Infants and Toddlers. J Am Diet Assoc. 2004;104(3):442-454. doi: 10.1016/j.jada.2004.01.027.

25. Secretaría de Salud. NORMA Oficial Mexicana NOM-043-SSA2-2012, Servicios básicos de salud. Promoción y educación para la salud en materia alimentaria. Criterios para brindar orientación. México: Diario Oficial de la Federación; 2012.

26. Jimenez-Cruz A, Bacardi-Gascon M, Pichardo-Osuna A, MandujanoTrujillo Z, Castillo-Ruiz O. Infant and toddlers' feeding practices and obesity amongst low-income families in Mexico. Asia Pac J Clin Nutr. 2010;19(3):316-323.

27. Keller A, Heitmann BL, Olsen N. Sugar-sweetened beverages, vascular risk factors and events: a systematic literature review. Public Health Nutr. 2015;18(7):1145-1154. doi: 10.1017/S1368980014002122.

28. Juonala M, Juhola J, Magnussen CG, Würtz P, Viikari JS, Thomson R, et al. Childhood environmental and genetic predictors of adulthood obesity: the cardiovascular risk in young Finns study. J Clin Endocrinol Metab. 2011;96(9):E1542-1549. doi: 10.1210/jc.2011-1243.

29. Juhola J, Oikonen M, Magnussen CG, Mikkilä V, Siitonen N, Jokinen E, et al. Childhood physical, environmental, and genetic predictors of adult hypertension: the cardiovascular risk in young Finns study. Circulation. 2012;126(4):402-409. doi: 10.1161/CIRCULATIONAHA.111.085977. 
30. Patel SA, Ali MK, Alam D, Yan LL, Levitt NS, Bernabe-Ortiz A, et al. Obesity and its Relation With Diabetes and Hypertension: A Cross-Sectional Study Across 4 Geographical Regions. Glob Heart. 2016;11(1):71-79 e4. doi: 10.1016/j.gheart.2016.01.003.

31.Van Grieken A, Renders CM, van de Gaar VM, Hirasing RA, Raat H. Associations between the home environment and children's sweet beverage consumption at 2-year follow-up: the 'Be active, eat right' study. Pediatr Obes. 2015;10(2):126-133. doi: 10.1111/ijpo.235.

32. Shefferly A, Scharf RJ, DeBoer MD. Longitudinal evaluation of $100 \%$ fruit juice consumption on BMI status in 2-5-year-old children. Pediatr Obes. 2016;11(3):221-227. doi: 10.1111/ijpo.12048.
33. Dennison BA, Rockwell HL, Baker SL. Excess fruit juice consumption by preschool-aged children is associated with short stature and obesity. Pediatrics. 1997;99(1):15-22.

34. Committee on nutrition. American Academy of Pediatrics: The use and misuse of fruit juice in pediatrics. Pediatrics. 2001;107(5):1210-1213.

35. Jiang JX, Lin LM, Lian GL, Greiner T. Vitamin A deficiency and child feeding in Beijing and Guizhou, China. World J Pediatr. 2008;4(1):2025. doi: 10.1007/s12519-008-0004-z.

36. Shim JS, Oh K, Kim HC. Dietary assessment methods in epidemiologic studies. Epidemiol Health. 2014; 36: e2014009. doi: 10.4178/epih/ e2014009. 